Poesia e Animalidade

AA 


\title{
APRESENTAR O IRREPRESENTÁVEL: paisagem com bois e vaca amarela
}

\author{
TO PRESENT THE IRREPRESENTABLE: \\ LANDSCAPE WITH OXEN AND YELLOW COW
}

Paula Glenadel*

Universidade Federal Fluminense/CNPq

\begin{abstract}
RESUMO
Aproximar o conto de Guimarães Rosa "Conversa de bois" (Sagarana, 1946) do quadro Vaca amarela (1911), de Franz Marc, pintor expressionista ligado ao movimento Der Blaue Reiter, significa repensar a representação dos animais, forçando os limites do comentário batailliano sobre a "mentira poética da animalidade" até fazer da poesia o lugar de uma verdade ética da hospitalidade com a qual se dá acolhida ao totalmente outro. Essa verdade se manifesta como exigência do impossível, como no dito de Derrida: "Um ato de hospitalidade só pode ser poético." No conto, coexistem estruturas mais tradicionais de representação com a tentativa poética de encontrar, através da plasticidade da linguagem, algo que seria traço irredutível dos bichos; no quadro, a representação da vaca vista de fora se mistura ao cromatismo em amarelo com o qual o pintor busca apresentar poeticamente algo do afeto dos bichos em sua "visão de mundo".
\end{abstract}

PALAVRAS - CHAVE

Animalidade, arte, Guimarães Rosa, Franz Marc

Se é certo que a arte moderna vem lidando sempre com aquilo que está no limite da representação, como o demonstram os processos históricos da passagem à abstração e a abrangência cada vez maior da arte conceitual e da performance, também não é menos certo que nos contornos da representação que ainda guarda uma figuralidade esconde-se um mistério, o mistério da incorporação do outro.

Em literatura ou em pintura, a figura é o claro enigma, escondido à vista de todos, na superfície, como a carta roubada de que Poe nos dá notícia. Ou a superfície lisa de um espelho. O enigma é percebido quando suspendemos a identificação com nossos modos de representação e, à maneira de Nietzsche, imaginamos um mundo em que um animal ou uma planta vissem tudo a partir de seu espelho:

* paulag@uol.com.br 
Para a planta o mundo é assim e assim, para nós assim e assim. Se compararmos as duas forças de percepção, nosso conceito de mundo vale para nós como sendo mais justo, isto é, como correspondendo mais à verdade. Ora, o homem se desenvolveu lentamente, e o conhecimento ainda está se desenvolvendo: a imagem do mundo torna-se, então, cada vez mais verdadeira e completa. Naturalmente isso é apenas um efeito de espelho, um reflexo cada vez mais claro. O próprio espelho não é em nada estranho ou sem relação com a essência das coisas, mas também nasceu lentamente, na qualidade de essência das coisas, similarmente. Nós vemos um esforço para tornar o espelho cada vez mais adequado: a ciência continua o processo natural. Assim, as coisas se refletem de uma maneira cada vez mais pura: liberação progressiva daquilo que é demasiado antropomórfico. Para a planta o universo inteiro é planta, para nós ele é homem. ${ }^{1}$

Mas, provavelmente, isso ainda é uma representação que atribui aos bichos um instinto de representar que, em última análise, talvez seja exclusivamente humano. Colocados como estamos, não podemos saber, é o que o trecho de Nietzsche nos sugere. À medida que o reflexo se refina, tendemos a esquecer do espelho.

O enigma da figura nos desafia a entender o que ocorre com a realização de uma função mental como a de "representar" e, sobretudo, por que ela ainda aparece como indissociável de nós e de nossa linguagem. A ciranda entre o sujeito representante e o objeto da representação torna-se, assim, uma dança trágica em que o nosso destino se joga. Seremos, algum dia, capazes de nos tornarmos outros?

Alguns artistas, como Guimarães Rosa e Franz Marc, encarando esse enigma, situam-se no extremo do possível do nosso pensamento, buscando uma representação que apresente os animais em sua obscura e luminosa singularidade sem aniquilá-los, sem torná-los um mesmo, mais ou menos distante de nós mesmos. Aproximar o conto de Rosa "Conversa de bois" (Sagarana, 1946) do quadro A vaca amarela (1911) de Marc, pintor expressionista ligado ao movimento Der Blaue Reiter, significa repensar a representação dos animais, forçando os limites do comentário batailliano sobre a "mentira poética da animalidade" até fazer da poesia o lugar de uma verdade ética da hospitalidade com a qual se dá acolhida ao totalmente outro.

Segundo Georges Bataille, "O animal abre frente a mim uma profundidade que me atrai e que me é familiar", ${ }^{2}$ mas todo discurso sobre ele só pode configurar uma "mentira poética da animalidade". ${ }^{3}$ Essa mentira é poética porque nos escapa enquanto saber, "substituindo ao nada da ignorância uma fulguração indistinta". ${ }^{4}$ Como Bataille, porém, apostando bem claramente nessa fulguração, Jacques Derrida reserva à poesia um lugar privilegiado na reflexão sobre a animalidade, numa formulação muito rica, à qual venho retornando muitas vezes: "Pois o pensamento do animal, se é que existe, toca à poesia, eis uma tese, e é aquilo do qual a filosofia, por essência, teve de privar-se. É a diferença entre um saber filosófico e um pensamento poético." ${ }^{5}$ Note-se aqui a sintonia com o pensamento de Nietzsche, que propõe: "O filósofo deve reconhecer o que faz necessidade e o artista deve criá-lo."

\footnotetext{
${ }^{1}$ NIETZSCHE. Le livre du philosophe/ Das Philosophenbuch, p. 110-111.

${ }^{2}$ BATAILLE. Théorie de la religion, p. 30.

${ }^{3}$ BATAILLE. Théorie de la religion, p. 27.

${ }^{4}$ BATAILLE. Théorie de la religion, p. 30.

${ }^{5}$ DERRIDA. L'animal que donc je suis, p. 258.

${ }^{6}$ NIETZSCHE. Le livre du philosophe/ Das Philosophenbuch, p. 47.
} 
Contudo, mesmo em poesia, essa verdade ética da acolhida ao animal em algum tipo de representação humana, longe de estar aí disposta, se manifesta como exigência do impossível, como no dito de Derrida: "Um ato de hospitalidade só pode ser poético."” Impossível, logo, necessário, e necessário como invenção, portanto, como poesia - essa é a dinâmica de um pensamento que demanda, segundo esse filósofo,

(...) uma outra maneira de pensar o filosófico em função de questões como a hospitalidade (convite, visita e toda uma cadeia de motivos associados: a promessa, o testemunho, o dom, o perdão, etc.), mas também de fazer a prova de um im-possível que não seria negativo. Tal prova implica um outro pensamento do acontecimento, do "ter-lugar": unicamente o im-possível tem lugar; e o desenvolvimento de uma potencialidade ou de uma possibilidade que já se encontra ali jamais fará um acontecimento ou uma invenção. ${ }^{8}$

Gesto recorrente em Derrida, ${ }^{9}$ a constatação da falta leva à invenção, e nesse sentido, remete ao potencial de criação que dorme na palavra poesia, como uma semente, que antes de germinar é dita "em dormência". Por isso, o impossível é o im-possível em Derrida, sempre por vir na sua potência germinativa.

No conto de Rosa, mestre nessa aproximação com os animais (lembro as onças de "Meu tio o Iauaretê", o sapo de "Tresaventura", a anta de "Tapiiraiauara"), coexistem estruturas mais tradicionais de representação, como a transcrição de pensamentos e sentimentos atribuídos aos animais pelo ser humano, com a tentativa poética de encontrar, através da plasticidade da linguagem, algo que seria traço irredutível dos bichos. É, como veremos, principalmente o caso dos nomes compostos expressando o estranhamento daquilo que nossa linguagem trata com naturalidade em uma única palavra, que pressupõe a unidade do fenômeno e sua tranquila identidade com o termo que o designa.

O conto, desde seu título - "Conversa de bois" -, tematiza a questão da representação, uma vez que não se pode saber ao certo se a conversa é entre eles, ou deles conosco, e começa com um diálogo sobre a possibilidade de fala dos bichos, que eu recorto segundo minha proposta de abordagem:

Que já houve um tempo em que êles conversavam, entre si e com os homens, é certo e indiscutível, pois que bem comprovado nos livros das fadas carôchas. Mas, hoje-em-dia, agora, agorinha mesmo, aqui, aí, ali e em toda a parte, poderão os bichos falar e serem entendidos, por você, por mim, por todo o mundo, por qualquer um filho de Deus? (...) - Falam, sim, senhor, falam!... (...)

- (...) Mas, e os bois? Os bois também?

- Ora, ora!... Esses é que são os mais!... Boi fala o tempo todo. Eu até posso contar um caso acontecido que se deu. ${ }^{10}$

\footnotetext{
${ }^{7}$ DERRIDA. De L'Hospitalité, Anne Fourmantelle invite Jacques Derrida à Répondre, p. 10.

${ }^{8}$ DERRIDA. Papel-máquina, p. 275.

${ }^{9}$ Fernanda Bernardo vem comentando a ética em Derrida em suas relações com o impossível, e destaca trechos fundamentais da sua obra: "Tout se passe comme si l'hospitalité était impossible: comme si la loi de l'hospitalité définissait cette impossibilité même." DERRIDA. De l'hospitalité, Anne Fourmantelle invite Jacques Derrida à Répondre, p. 71. Veja-se o excelente texto da pesquisadora em: < http://www.uc.pt/ fluc/dfci/publicacoes/a_etica_da_hospitalidade_II $>$.

${ }^{10}$ ROSA. Conversa de bois, p. 283. Mantive a grafia da edição de 1967 nas citações.
} 
A possibilidade de fala dos bichos é apresentada simultaneamente como pertencendo a outro tempo e a outra realidade, porém graciosamente afirmada, ao invés de posta em dúvida por essas duas características. E o conto, tendo encontrado assim seu dispositivo narrativo, segue narrando o episódio do carro de bois puxado por quatro pares desses animais, cada um com um nome, uma pelagem, uma compleição e um temperamento.

O conto teria sido transmitido ao narrador por Manuel Timborna, que, por sua vez, o obtivera da irarinha curiosa capturada por ele, que "só pôde recobrar a liberdade a trôco da minuciosa narração", ${ }^{11}$ aparecendo como uma interessante Sherazade animal, cujo destino está entrelaçado ao processo de narrar. Nesse encadeamento narrativo, o olhar da irara é apresentado como o do narrador-testemunha das cenas, o que já é uma tentativa de inserir a história numa moldura "animal".

Os bois são limítrofes, pois, além de mugirem e bufarem em onomatopeia, podem "pensar como o homem e como os bois", ${ }^{12}$ o que confere ao conto uma capacidade de refletir sobre as duas formas de representação que utiliza, e que tentamos aqui discernir. Assim, o pensamento de Brilhante, por exemplo, traduzido em linguagem argumentativa, representa o boi do ponto de vista do humano, uma ontologia do "ser boi-de-carro", desdobrada em nós somos los outros bois não são:

Nós somos bois... bois-de-carro... Os outros, que vêm em manadas, para ficarem um tempodas-águas pastando na invernada, sem trabalhar, só vivendo e pastando, e vão-se embora para deixar lugar aos que chegam magros, êsses todos não são como nós... ${ }^{13}$

Os bois aprenderam a pensar no convívio com o homem, ${ }^{14}$ diz o narrador, como que situando a genealogia dessa representação mais humanizada. E, como filósofos, os bois também são capazes de pensar no que é pensar - é bom, se for nas coisas mansas e bonitas; por outro lado, as coisas ruins pensadas são piores. ${ }^{15}$

Contudo, a apresentação do carreiro Agenor Soronho como o "homem-de-paucomprido-com-o marimbondo-na-ponta" 16 sinaliza esse tipo de invenção poética que permeia o conto. Assim, temos uma sucessão de nomes compostos: o "boi-grande-que-berrafeio-e-carrega-uma-cabaça-na-cacunda", ${ }^{17}$ o zebu. "O-que-gosta-de-pastar-à-beira-dacêrca-do-pasto-das-vacas", ${ }^{18}$ o boi Brabagato. "O-que-deita-para-se-esconder-no-meio-domeloso-alto", ${ }^{19}$ o boi Namorado. "O-que-tem-cabeça-grande-e-murundu-nas-costas", ${ }^{20} \mathrm{o}$ boi Dansador. O "bezerro-de-homem-que-caminha-sempre-na-frente-dos-bois", ${ }^{21}$ Tiãozinho,

\footnotetext{
${ }^{11}$ ROSA. Conversa de bois, p. 286.

${ }^{12}$ ROSA. Conversa de bois, p. 289.

${ }^{13}$ ROSA. Conversa de bois, p. 287-288.

${ }^{14}$ ROSA. Conversa de bois, p. 290.

${ }^{15}$ ROSA. Conversa de bois, p. 290.

${ }^{16}$ ROSA. Conversa de bois, p. 288.

${ }^{17}$ ROSA. Conversa de bois, p. 288.

${ }^{18}$ ROSA. Conversa de bois, p. 291.

${ }^{19}$ ROSA. Conversa de bois, p. 291.

${ }^{20}$ ROSA. Conversa de bois, p. 315.

21 ROSA. Conversa de bois, p. 313.
} 
o guia. $\mathrm{Ou}$ "aquêle-que-tem-um-anel-branco-ao-redor-das-ventas", ${ }^{22}$ figura da união da força de todos os bois. O "boi-da-noite-que-saiu-do-mato", ${ }^{23}$ Brilhante. É ele quem fica procurando, quem "pensa falado" 24 algo que lhe escapa sempre e que tem a ver com o homem, algo ensinado pelo "boi que pensava de homem, o-que-come-de-ôlho-aberto", ${ }^{25}$ o boi Rodapião, levado a um triste fim pela sua esperteza quase humana, que faz pensar em Prometeu, devorado, desta vez, por urubus.

Em função da tristeza do menino trabalhador, pobre e desprotegido, com o pai morto sendo levado no carro, sofrendo os maus-tratos e a brutalidade do carreiro como os bois, vai ocorrendo uma assimilação aos animais. Assim, o carreiro se dirige a ele: "Vam'bora, lerdeza! Tu é bôbo e mole; tu é boi?"26 O menino vê os bois, sentindo-se olhado por eles: "Que santos de grandes, e cheirando forte a bondade, bois companheiros, que não fazem mal a ninguém; criação certa de Deus, olhando com os olhos quietos de pessoa amiga da gente!" 27 Os bois observam que o menino "dorme caminhando, como nós sabemos fazer" ${ }^{28}$ e que ele, "quando está meio dormindo, pensa quase como nós bois". ${ }^{29}$

O desfecho do conto nos mostra uma espécie de interação entre todos os bois e o menino-bezerro, no sentido de se afirmarem contra Agenor Soronho, quando tudo fica "escuro, brilhante, grande e forte", e eles se tornam um só- esta seria a manifestação de um "pensar-boi" no espaço do conto. Os bois desejam que o menino grite e eles tenham de arrancar depressa, derrubando assim o carreiro adormecido. No seu estado de semivigília, com efeito, o menino grita para os bois andarem e a morte de Soronho acontece.

Alternam-se, portanto, nesse conto, os dois tipos de representação, uma "exterior", mesmo quando representa o íntimo dos bois e seus pensamentos: ela vai do humano ao animal. A outra representação é a que eu gostaria de chamar de apresentação, e que encena um trajeto poético que fosse do animal ao humano. É como se o animal pudesse atravessar a linguagem humana e chegar a dizer-se em uma combinação lexical inédita, traduzindo sua visão de mundo. Evidentemente, o conhecimento que Rosa tinha de várias línguas, dando-lhe uma consciência generalizada da tradução, faz com que a formação de palavras lhe seja um processo familiar, ainda que, por isso mesmo, desnaturalizado. Processo empregado, nesse caso, para inquietar as fronteiras entre Darstellung e Vorstellung, no sentido daquilo que Georges Didi-Huberman caracteriza como uma "estética da imanência", a propósito do poeta Victor Hugo. ${ }^{30}$

\footnotetext{
${ }^{22}$ ROSA. Conversa de bois, p. 315.

${ }^{23}$ ROSA. Conversa de bois, p. 292.

${ }^{24}$ ROSA. Conversa de bois, p. 296.

${ }^{25}$ ROSA. Conversa de bois, p. 296.

${ }^{26}$ ROSA. Conversa de bois, p. 304.

${ }^{27}$ ROSA. Conversa de bois, p. 304.

${ }^{28}$ ROSA. Conversa de bois, p. 313.

${ }^{29}$ ROSA. Conversa de bois, p. 314.

30 "Este é o sentido radical de uma estética da imanência: ela se deseja gesto e não representação, Darstellung e não Vorstellung, processo e não aspecto, contato e não distância. Ela é teatro: ela tenta encenar, reencenar em sua minúscula escala - uma mesa, uma folha de papel, tinta e uma pena - o grande jogo do 'mistério da vida”" (DIDI-HUBERMAN. A imanência estética, p. 143).
} 
Vem dos bois de Rosa uma interessante inversão quanto aos impasses da representação, nesse caso, propondo que o homem seria o verdadeiro irrepresentável:

O homem é um bicho esmochado, que não devia haver. Nem convém espiar muito para o homem. É o único vulto que faz ficar zonzo, de se olhar muito. É comprido demais, para cima, e não cabe todo de uma vez, dentro dos olhos da gente. ${ }^{31}$

No quadro de Franz Marc, a representação da vaca vista de fora se mistura ao cromatismo em amarelo com o qual o pintor busca apresentar poeticamente algo do afeto dos bichos em sua "visão de mundo". Envolvido, com o russo Wassily Kandinsky e outros pintores, na aventura de dar um sentido espiritual à pintura, Marc experimenta pintar na fronteira da desidentificação com o sujeito que pinta e na identificação com o objeto representado. De início, isso o leva aos animais. Posteriormente, a algo mais próximo da abstração. Sua obra é cedo interrompida por sua morte no front de batalha da Primeira Grande Guerra.

Esse interlocutor entusiasmado do Cubismo (e, em seguida, do Futurismo) atribuía à arte da sua época a capacidade de revolucionar a maneira de pensar o mundo. Seu objetivo em pintura era o de "sentir mais o ritmo orgânico de todas as coisas", o de tentar identificar-se "de maneira panteísta com as vibrações, os fluxos de sangue na natureza, nas árvores, nos animais, no ar". ${ }^{32}$ Porém, apesar desse direcionamento à natureza, Marc não era naturalista, como explica:

A arte sempre foi e é em sua essência o afastamento mais temerário da natureza e do "natural" que jamais existiu; ela é a ponte para o reino do espírito, a necromancia da humanidade. ${ }^{33}$

E acrescenta, quanto à sua resistência frente à forma naturalista, que ela

(...) não deriva de um capricho ou de uma busca de originalidade, ela é na verdade a consequência de uma vontade bem mais profunda que inflama nossa geração: a sede de conhecimento das leis metafísicas, sede até agora detida apenas pelos filósofos. ${ }^{34}$

O que lhe interessava eram os grandes princípios organizadores da matéria; nisso residia a dimensão espiritual da sua obra. Como os cubistas, que estudavam matemática e dela obtinham não uma confirmação empírica dos nossos modos de representação, definidos por Apollinaire como a "antiga arte das ilusões de ótica e das proporções locais", 35 mas antes uma imagem do nosso pensamento e da nossa visão.

É nesse contexto de questionamentos que se localiza a pintura animal de Marc:

Há para o artista ideia mais misteriosa do que imaginar a maneira como a natureza se reflete no olho de um animal? Como um cavalo vê o mundo? Ou uma águia, um cervo ou um cão? Como é miserável, sem alma, nossa convenção [hábito] de colocar os animais em

\footnotetext{
${ }^{31}$ ROSA. Conversa de bois, p. 288.

${ }^{32}$ MARC. Écrits et correspondances, p. 92, tradução minha

${ }^{33}$ MARC. Écrits et correspondances, p. 150, tradução minha.

${ }^{34}$ MARC. Écrits et correspondances, p. 157, tradução minha.

${ }^{35}$ APOLLINAIRE. Méditations esthétiques, p. 12.
} 
uma paisagem que corresponde a nossa visão, em vez de mergulharmos na alma do animal a fim de adivinhar seu campo de imagens. ${ }^{36}$

Nesse trabalho espiritual, as cores ganham uma especial importância. A cada uma das cores básicas corresponde uma intensidade afetiva específica, que poderíamos resumir assim: azul, "princípio masculino, austero e espiritual"; amarelo, "princípio feminino, suave, alegre e sensual;" vermelho, "a matéria, brutal e pesada". ${ }^{37}$ Tais são os princípios básicos desse sistema, mas a composição depende também das quantidades, das massas de cores, bem como do seu entrechoque.

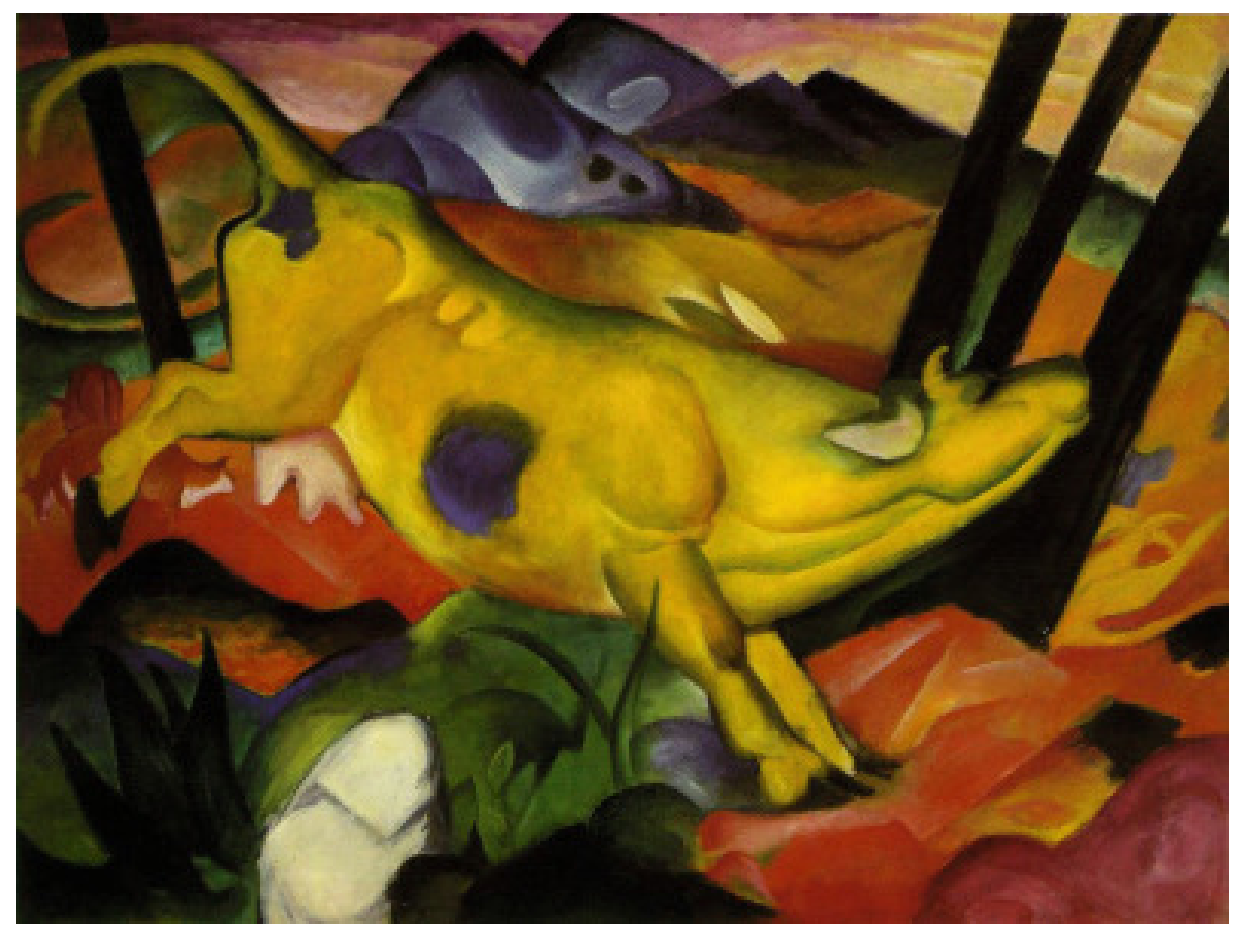

FIGURA 1 - Franz Marc, Vaca amarela, 1911

O quadro de 1911 mostra uma vaca que ocupa quase a totalidade da sua superfície, estendendo-se numa paisagem montanhosa e com três vacas alaranjadas ao fundo esquerdo. $\mathrm{O}$ azul vem assinalar a espiritualidade, compensando o amarelo, num jogo de dissonância caro a Kandinsky e aos expressionistas. Essa cor azul comparece no corpo da vaca, numa mancha arredondada na altura do seu estômago ou coração, e prolonga-se por detrás da vaca na crista de uma das montanhas em diferentes tonalidades de azul que marcam o centro do quadro. No meio do corpo da vaca, o azul faz a passagem entre o torso e pescoço, amplos e muito musculosos, e a fragilidade do quarto traseiro, mais estreito, onde sobressaem as tetas em rosa claro. Outra mancha azul na base do rabo alinha-se perfeitamente com o começo da pequena cadeia de montanhas azuis, o que parece suspender a vaca no ar, elevando a sua figura. A vaca aparenta-se às montanhas. Mais concentradas à direita, uma à esquerda, hastes escuras sugerem troncos de árvores,

${ }^{36}$ MARC. Écrits et correspondances, p. 143, tradução minha.

${ }^{37}$ MARC. Écrits et correspondances, p. 301, tradução minha. 
cuja copa não se vê. A vaca está compreendida, abrigada entre elas. Outras cores, como o verde e o branco, aparecem em massas bem menores, nas folhagens dispersas e em uma forma ovalada que sugere uma pedra. Nota-se a ausência de vermelho puro, considerada como cor agressiva; segundo Marc, "ele é a cor que sempre deve ser combatida e vencida pelas duas outras!" 38

De olhos fechados, a vaca parece exalar calma e satisfação. Ela está, por assim dizer, no centro do seu mundo. Daí provém a força e a expressividade da apresentação da vaca realizada por Franz Marc, na tentativa de, como Guimarães Rosa, nos fazer compartilhar uma visão do mundo radicalmente outra.

A perspectiva da arte como "necromancia da humanidade" reaviva, desse modo, o enigma da representação. No começo de 1913, à beira da Primeira Guerra Mundial, no seu caderno de croquis, meditando sobre uma imagem em que uma mulher, grande e vermelha, se conjuga a outros elementos, como o relâmpago e o "anjo do temor" que bate à janela, Marc anota: "eu via estremecer o coração vermelho da mulher e os gatinhos negros sobre a mesa verde - o que é [?], vermelho e negro e verde? Três cores fazem um pensamento?"39

\section{A}

\section{RÉ SUMÉ}

Rapprocher le récit de Guimarães Rosa "Conversa de bois" ([Conversation de bœufs] 1946) du tableau Vache jaune (1911), de Franz Marc, peintre expressionniste lié au mouvement Der Blaue Reiter, signifie repenser la représentation des animaux, en forçant les limites du commentaire bataillien sur le "mensonge poétique de l'animalité" jusqu'à faire de la poésie le lieu d'une vérité éthique de l'hospitalité avec laquelle on accueille le tout autre. Cette vérité se manifeste comme exigence de l'impossible, comme dans le dit de Derrida: "Un acte d'hospitalité ne peut être que poétique." Dans le récit, des structures plus traditionnelles de représentation coexistent avec la tentative poétique de trouver, grâce à la plasticité du langage, quelque chose qui serait un trait irréductible des bêtes; dans le tableau, la représentation de la vache vue du dehors se mêle au chromatisme en jaune avec lequel le peintre cherche à présenter poétiquement quelque chose de l'affect des bêtes dans leur "vision du monde".

\section{OTS - CLÉ}

Animalité, art, Guimarães Rosa, Franz Marc

\footnotetext{
${ }^{38}$ MARC. Écrits et correspondances, p. 301, tradução minha.

${ }^{39}$ MARC. Écrits et correspondances, p. 183, tradução minha.
} 


\section{REFERÊNCIAS}

APOLLINAIRE, Guillaume. Sur la peinture In: . Euvres en prose complètes. Paris: Gallimard, 1991. p. 5-18. t. II.

BATAILlE, Georges. Théorie de la religion. Paris: Gallimard, 1973.

DERRIDA, Jacques. De L'hospitalité, Anne Fourmantelle invite Jacques Derrida à répondre. Paris: Calmann-Lévy, 1997.

DERRIDA, Jacques. L'animal que donc je suis. In: . MALLET, M.-L. (Org.) L'animal autobiographique. Autour de Jacques Derrida. Paris: Galilée, 1999. p. 251-301.

DERRIDA, Jacques. Papel-máquina. Trad. Evando Nascimento. São Paulo: Estação Liberdade, 2004.

DIDI-HUBERMAN, Georges. A imanência estética. Trad. Marcelo Jacques de Moraes. Revista Alea, v. 5, n. 1, p. 118-147, jul. 2003.

MARC, Franz. Écrits et correspondances. Trad. Thomas de Kayser. Paris: École Nationale Supérieure des Beaux-Arts, 2006.

NIETZSCHE, Friedrich. Le livre du philosophe/Das Philosophenbuch. Ed. bilíngue. Trad. Angèle K. Marietti. Paris: Aubier-Flammarion, 1969.

ROSA, João Guimarães. Conversa de bois. In: . Sagarana. Rio de Janeiro: J. Olympio, 1967. p. 283-318. 